\title{
Clinicopathological and biological significance of mitotic centromere-associated kinesin overexpression in human
} gastric cancer

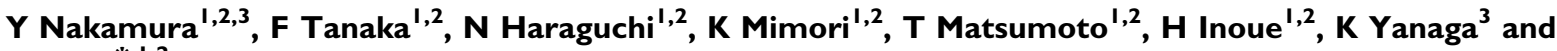 \\ M Mori ${ }^{*, 1,2}$
}

'Department of Surgery and Molecular Oncology, Medical Institute of Bioregulation, Kyushu University, 4546 Tsurumibaru, Beppu 874-0838, Japan;

${ }^{2}$ Core Research for Evolutional Science and Technology (CREST), Japan Science and Technology Agency (IST), 4- I-8 Honcho Kawaguchi, Saitama, Japan;

${ }^{3}$ Department of Surgery, Jikei University School of Medicine, 3-25-8 Nishi-shinbashi, Minato-ku, Tokyo, Japan

\begin{abstract}
Mitotic centromere-associated kinesin (MCAK) is a microtubule (MT) depolymerase necessary for ensuring proper kinetochore MT attachment during spindle formation. To determine MCAK expression status and its clinicopathological significance, real-time reverse transcriptase-polymerase chain reaction was used in 65 cases of gastric cancer. MCAK gene expression in cancer tissue was significantly higher than expression in non-malignant tissue $(P<0.05)$. Elevated MCAK expression was significantly associated with lymphatic invasion $(P=0.01)$ and lymph node metastasis $(P=0.04)$. Furthermore, patients with high MCAK expression had a significantly poorer survival rate than those with low MCAK expression $(P=0.008)$. Immunohistochemical study revealed that expression of MCAK was primarily observed in cancer cells. Additionally, a gastric cancer cell line (AZ52I) that stably expressed MCAK was established and used to investigate the biological effects of the MCAK gene. In vitro results showed that cells transfected with MCAK had a high rate of proliferation $(P<0.00 \mathrm{I})$ and increased migratory ability $(P<0.00 \mathrm{I})$ compared to mock-transfected cells. This study demonstrated that elevated expression of MCAK may be associated with lymphatic invasion, lymph node metastasis, and poor prognosis. These characteristics may be due in part to the increased proliferative and migratory ability of cells expressing MCAK.
\end{abstract}

British Journal of Cancer (2007) 97, 543-549. doi:I0.1038/sj.bjc.6603905 www.bjcancer.com

Published online 24 July 2007

(c) 2007 Cancer Research UK

Keywords: MCAK; KIF2C; gastric cancer; migration; cancer testis antigen

Gastric cancer is the fifth most common malignancy and the second leading cause of cancer death in the world. Significant geographic variation exists, with high-risk areas such as Japan, Eastern Asia, and Central and South America (Terry et al, 2002; Sakamoto et al, 2004). The incidence is relatively low in the United States; however, gastric cancer is a significant cause of morbidity and mortality, with 23000 cases per year, resulting in 12000 annual deaths (Jemal et al, 2004). To improve survival rate, development of novel treatments is crucial, and new molecular targets are desirable.

Mitotic centromere-associated kinesin (MCAK), which is a member of kinesin-13, is found throughout the cell, and is especially concentrated at the centromeres, kinetochores, and spindle poles (Wordeman and Mitchison, 1995). Kinesin family (KIF) proteins with the kinesin motor catalytic domain and the coiled-coil domain are microtubule (MT)-dependent molecular motors (Brady, 1985; Vale et al, 1985; Hirokawa et al, 1989; Endow, 2003). Members of the kinesin superfamily play an important role

*Correspondence: Dr M Mori; E-mail: mmori@beppu.kyushu.ac.jp Received 15 April 2007; revised 28 June 2007; accepted 28 June 2007; published online 24 July 2007 in intracellular transport and cell division (Wittmann et al, 2001). The MT cytoskeleton is a dynamic structure in which the length of the MTs is tightly regulated. One regulatory mechanism is depolymerisation of MTs by motor proteins in the kinesin-13 family (Helenius et al, 2006). The human genome has three distinct genes encoding the following kinesin-13 family members: Kif2a (chromosome 5q12), Kif2b (chromosome 17q22), and MCAK/Kif2c (chromosome 1p34). Unlike other kinesins that transport cargo, MCAK and other kinesin-13 members catalyse MT disassembly, a key element in normal chromosome movement (Maney et al, 1998; Helenius et al, 2006). Overexpression of wild-type MCAK is known to induce depolymerisation of MTs in both mitotic and interphase cells (Kline-Smith and Walczak, 2002).

Regarding the association of MCAK with cancer, increased levels of both MCAK and the Aurora kinases have been reported to be correlated with tumorigenesis (Perou et al, 1999). Overexpression of MCAK causes a moderate increase in the frequency of multipolar spindles (Holmfeldt et al, 2004) and monopolar spindles (Kline-Smith and Walczak, 2002), which could contribute to the gain or loss of chromosomes in daughter cells. Mitotic centromere-associated kinesin mRNA was reported to be highly 
expressed in colon cancer tissue (Mori et al, 1993; Scanlan et al, 2002). There have been no reports on the functional analysis of MCAK expression in human gastric cancer, the second most common cancer in Japan.

In this study, we examined the clinicopathological and prognostic significance of MCAK expression in gastric cancers. We report on the overexpression of MCAK and the association of MCAK expression with lymphatic invasion, lymph node metastasis, and poor prognosis in gastric cancer.

\section{MATERIALS AND METHODS}

\section{Clinical cases}

Patients and sample collection Primary gastric cancer specimens and matched control samples were obtained from 65 patients who underwent surgery at the Medical Institute of Bioregulation Hospital, Kyushu University. All specimens were immediately frozen in liquid nitrogen and stored at $-80^{\circ} \mathrm{C}$ until RNA extraction. Written informed consent was obtained from all patients. Whenever possible, specimens were also prepared for immunohistochemical studies. All 65 patients were clearly identified as having gastric cancer, based on the clinicopathologic findings. No patients received chemotherapy or radiotherapy before surgery. All patients were closely followed after surgery at regular 1-month intervals. The follow-up periods ranged from 2 to 67 months, with a mean of 30 months. All data, including age, sex, serosal invasion, lymphatic invasion, lymph node metastasis, vascular invasion, liver metastasis and histology were obtained from the clinical and pathologic records.

Total RNA extraction Frozen tissue specimens were homogenised in guanidium thiocyanate, and total RNA was obtained by ultracentrifugation through a cesium chloride cushion, as described previously (Mori et al, 1993).

Evaluation of MCAK expression in clinical samples As described previously, cDNA was synthesised from $8.0 \mu \mathrm{g}$ of total RNA (Inoue et al, 1995). The glyceraldehyde-3-phosphate dehydrogenase $(G A P D H)$ gene served as an internal control. Two gene-specific oligonucleotide primers were designed: $(M C A K)$ sense, $5^{\prime}$-GATGG AAGCCTGCTCTAACG-3'; antisense, $5^{\prime}$-GAGCAGATTCCGCTTTG TTC-3'; (GAPDH) sense, 5'-TTGGTATCGTGGAAGGACTCA-3'; antisense, $5^{\prime}$-TGTCATCATATTTGGCAGGTT- $3^{\prime}$. The following temperature profile was used: initial denaturation at $95^{\circ} \mathrm{C}$ for $10 \mathrm{~min}$, followed by 40 cycles of denaturation at $95^{\circ} \mathrm{C}$ for $10 \mathrm{~s}$, annealing at $66^{\circ} \mathrm{C}\left(60^{\circ} \mathrm{C}\right.$ for $\left.G A P D H\right)$ for $10 \mathrm{~s}$, and extension at $72^{\circ} \mathrm{C}$ for $10 \mathrm{~s}$. PCRs were performed in a LightCyclerTM system (Roche Applied Science, Indianapolis, IN, USA) using the LightCycler FastStart DNA Master SYBR Green I Kit (Roche Applied Science), as described previously (Ogawa et al, 2004). All concentrations were calculated relative to the concentration of the cDNA from Human Universal Reference total RNA (Clontech, Mountain View, CA, USA), and the concentration of MCAK was then divided by the concentration of endogenous reference $(G A P D H)$ to obtain normalised expression values (Bieche et al, 1998 a, b, 1999). Each assay was performed three times to verify the results, and the mean normalised value of mRNA expression was used for subsequent analysis.

Immunohistochemistry Immunohistochemical studies of surgical specimens for MCAK expression were performed on formalinfixed, paraffin-embedded tissues from gastric cancer patients. After deparaffinisation and blocking of tissue sections, primary goat polyclonal antibody against MCAK (Abcam, Cambridge, UK) was applied at a 1:100 dilution, and the antigen - antibody reaction was incubated overnight at $4^{\circ} \mathrm{C}$. ENVISION reagents (ENVISION + Dual Link/HRP; Dako Cytomation, Glostrup, Denmark) were used to detect the antigen-antibody reaction. All tissue sections were counterstained with haematoxylin.

\section{Experimental studies}

Cell lines The cell lines derived from human gastric cancer cell AZ521, KATO3, MKN1, MKN7, MKN28, MKN45, MKN74, NUGC3, NUGC4, SH10TC, and the human fibrosarcoma cell HT1080 were obtained from the Cell Resource Center for Biomedical Research Institute of Development, Aging and Cancer (Tohoku University, Sendai, Japan) and maintained in RPMI-1640 medium containing $10 \%\left(\mathrm{vv}^{-1}\right)$ fetal bovine serum (FBS) and antibiotics at $37^{\circ} \mathrm{C}$ in a $5 \%$ humidified $\mathrm{CO}_{2}$ atmosphere.

DNA transfection The MCAK gene expression vector (EGFPHsMCAK) was a generous gift from Professor Linda Wordeman (University of Washington School of Medicine, Seattle, WA, USA) (Moore and Wordeman, 2004). To confirm accurate insertion into the frame of the expression vector, sequencing chemistry was performed. AZ521, a gastric cancer cell line, did not express $M C A K$ mRNA among 10 gastric cancer cell lines (data not shown). Therefore, AZ521 was used for the transfection assays. The FuGENE 6 (cat. \# 1815091; Roche Applied Science) transfection reagent was employed to establish permanently transfected cells, which were then selected by treatment with the antibiotic G418 (Invitrogen, Carlsbad, CA, USA) to the specific clone for in vitro assays, as described previously (Adrain et al, 1999).

Western blot analysis Western blotting and immunocytochemical staining were used to confirm the expression of MCAK in the EGFP-HsMCAK- and mock-transfected cells. Total protein was extracted from samples using PRO-PREP protein extraction solution (iNtRON Biotechnology Inc., Kyungi-Do, Korea). Aliquots of total protein were applied to $10 \%$ acrylamide gradient gels. After electrophoresis, the samples were electroblotted $(0.2 \mathrm{~A}, 120 \mathrm{~min}$, $4{ }^{\circ} \mathrm{C}$ ) onto a polyvinylidene membrane (Immobilon; Millipore Inc., Bedford, MA, USA). The MCAK protein was detected with goat polyclonal antibody at a $1: 250$ dilution. The protein levels of MCAK were normalised to the level of $\beta$-actin protein, which was detected by a $1: 1000$ dilution of anti- $\beta$-actin antibody (Cytoskelton Inc., Denver, CO, USA). The blots were developed using horseradish peroxidase-conjugated anti-goat immunoglobulin (Promega Inc., Madison, WI, USA) at a dilution of $1: 5000$. Signals were detected using SuperSignal (Pierce Biotechnology Inc., Rockford, IL, USA).

In vitro assays The 3-(4,5-dimethylthiazol-2-yl)-2,5-diphenyltetrazolium bromide (MTT) assay (Roche Diagnostics Corp. GmbH, Mannheim, Germany) was used to determine cell proliferation. Logarithmically growing MCAK- and mock-transfected AZ521 cells were seeded at $5.0 \times 10^{3}$ cells well $^{-1}$ in 96-well flat-bottomed microtitre plates, in a final volume of $100 \mu \mathrm{l}$ culture medium per well, and incubated in a humidified atmosphere $\left(37^{\circ} \mathrm{C}\right.$ and $5 \%$ $\mathrm{CO}_{2}$ ). After incubation, $10 \mu \mathrm{l}$ of MTT labeling reagent (final concentration $0.5 \mathrm{mg} \mathrm{ml}^{-1}$ ) was added to each well, and the plate was incubated for $4 \mathrm{~h}$ in a humidified atmosphere. Solubilisation solution $(100 \mu \mathrm{l})$ was added to each well, and the plate was incubated overnight in a humidified atmosphere. After confirmation that the purple formazan crystals were completely solubilised, the absorbance of each well was measured by a Model 550 series microplate reader (Bio-Rad Laboratories, Hercules, CA, USA), at a wavelength of $570 \mathrm{~nm}$ corrected to $655 \mathrm{~nm}$. Each independent experiment was performed three times.

For cell cycle analysis, MCAK- and mock-transfected AZ521 cells $\left(2.0 \times 10^{6}\right)$ were preincubated for $24 \mathrm{~h}$ in $10 \mathrm{ml}$ of serum-free medium at $37^{\circ} \mathrm{C}$, and were then incubated in medium containing $10 \%$ FBS $\left(\mathrm{v} \mathrm{v}^{-1}\right)$ for an additional $18 \mathrm{~h}$ at $37^{\circ} \mathrm{C}$. The cells were harvested and fixed in $70 \%$ ethanol at $-20^{\circ} \mathrm{C}$, and then washed and 
resuspended in propidium iodide (PI) (BD Biosciences, San Jose, CA, USA) staining buffer containing $5 \mu \mathrm{g}$ PI and $0.25 \mathrm{mg}$ RNase per millilitre PBS. DNA content was measured with an EPICS XL flow cytometer (Beckman Coulter Corp., Tokyo, Japan).

Migration assays were performed using BD Falcon FluoroBlock $8 \mu$ m HTS Cell Culture Inserts for 24-well plates (cat. \# 351152; BD Biosciences) to evaluate invasive cells, as described previously (Albini et al, 1987). Briefly, cells $\left(5.0 \times 10^{4}\right.$ cells per $0.5 \mathrm{ml}$ per well) were placed in the upper chamber, and the lower chamber was filled with $750 \mu$ l DMEM with $10 \%\left(\mathrm{v} \mathrm{v}^{-1}\right)$ fetal calf serum as a chemoattractant. After 24,36 , and $48 \mathrm{~h}$ of incubation at $37^{\circ} \mathrm{C}$, insert membranes were labeled with calcein-AM reagent (Molecular Probes, Carlsbad, CA, USA). Migrating cells that had passed through the membrane to its lower surface were evaluated in a fluorescence plate reader (Perkin-Elmer, Waltham, MA, USA) at excitation/emission wavelengths of $485 / 530 \mathrm{~nm}$. Migratory ability was calculated from the ratio of fluorescence of the MCAK- or mock-transfected AZ521 cells to the fluorescence of the invasive cells of HT1080, the human fibrosarcoma cell line that served as a control.

Anoikis assays were performed in six-well Costar Ultra Low Attachment Microplates (cat. \# 3471; Corning Inc., Corning, NY, USA). Mitotic centromere-associated kinesin- or mock transfected AZ521 cells were suspended in RPMI-1640 with $10 \%$ FBS at a level of $0.5 \times 10^{6} \mathrm{cells} \mathrm{ml}^{-1}$, and $2 \mathrm{ml}$ of cell suspension was added to each well and incubated in the microplates for $18 \mathrm{~h}$ in a humidified $\left(37^{\circ} \mathrm{C}\right.$ and $\left.5 \% \mathrm{CO}_{2}\right)$ incubator. Following the induction of anoikis, the cells were washed and resuspended in $0.5 \mathrm{ml}$ of binding buffer, and annexin V:fluorescein isothiocyanate/PI labeling was performed in accordance with the manufacturer's protocol (BD Biosciences). Analysis was performed by FACScan (BD Biosciences). Each sample contained $1 \times 10^{4}$ cells. The data were analysed by CellQuest software (BD Biosciences). These procedures were also performed in triplicate.

\section{Statistical analysis}

Quantitative real-time reverse transcriptase-polymerase chain reaction (RT-PCR) data and in vitro transfected cell assay data were analysed by JMP 5 for Windows software (SAS Institute Inc., Cary, NC, USA). Patient's overall survival rates were calculated actuarially according to the Kaplan-Meier method (Kaplan and Meier, 1958) and were measured from the day of surgery. Differences between groups were estimated using the $\chi^{2}$ test, Student's $t$-test, repeated-measures ANOVA test, and the log-rank test (Mantel, 1966). Variables with a value of $P<0.1$ in univariate analysis were used in a subsequent multivariate analysis based on the Cox proportional hazards model. A probability level of 0.05 was chosen for statistical significance.

\section{RESULTS}

\section{Clinical cases}

Mitotic centromere-associated kinesin expression in clinical samples Reverse transcriptase-polymerase chain reaction analysis of four representative clinical tissue samples demonstrated unequivocal $M C A K$ mRNA expression in cancer samples compared with negative expression in the paired samples of adjacent normal tissue (Figure 1A). To investigate the high level of MCAK expression in the initial cancer samples, all 65 paired clinical samples of gastric cancers were then submitted for quantitative real-time RT-PCR analysis. There were 43 of 65 patients $(66.2 \%)$ with a higher expression level of $M C A K$ mRNA in gastric cancer
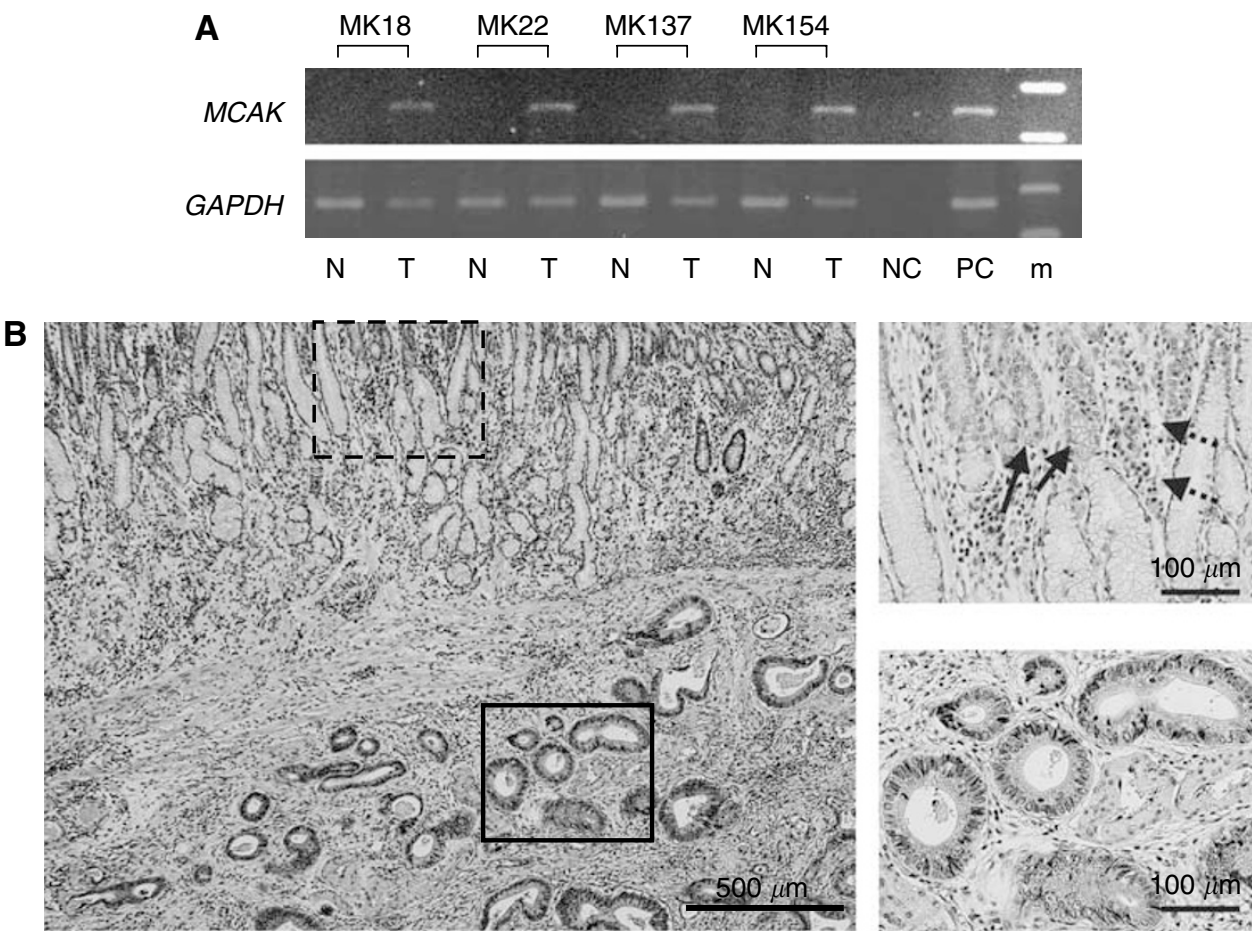

Figure I Mitotic centromere-associated kinesin mRNA expression in clinical samples. (A) RT-PCR analysis of MCAK in gastric cancer ( $T$ ) and paired normal $(\mathrm{N})$ samples obtained from four patients (patient numbers: MK 18, 22, I37, and I54). Mitotic centromere-associated kinesin mRNA expression was observed in cancer samples, but no expression was seen in normal samples. GAPDH was used as a control. $\mathrm{m}=$ marker; $\mathrm{NC}=$ negative control; $\mathrm{PC}=$ positive control. (B) Immunohistochemistry of gastric cancer surgical specimens using an antibody to MCAK. Positive staining was observed in cancer cells, but not in normal mucosal epithelium (magnification $\times 40$ (left image)). A dotted circle indicates normal mucosa and a solid line circle indicates cancer cells. In normal mucosa (right upper image, magnification $\times 100$ ), solid line arrows indicate proliferating cells of the glandular neck and dotted line arrows indicate macrophages. 
tissues than in non-malignant tissues. The mean expression value of $M C A K$ mRNA in cancer tissues was $0.25 \pm 0.015$ (mean \pm s.d., normalised by GAPDH gene expression), which was significantly higher than the value of $0.18 \pm 0.025$ in the corresponding nonmalignant tissues $(P=0.0145$; Student's $t$-test $)$. Figure 1B shows the immunohistochemical result of a representative clinical sample from a gastric cancer patient. Most of the staining is seen in the cytoplasm of cancer cells, proliferating cells of glandular neck, and macrophage, and not in stromal cells or normal epithelium. Thus, proliferating cells demonstrated high MCAK expression.

Clinicopathologic and prognostic analyses of gastric cancers In the current study, patients with less than the median MCAK mRNA expression ratio of cancerous to normal tissue $(\mathrm{T} / \mathrm{N})$ were assigned to the low-expression group $(n=33)$, and the others were assigned to the high-expression group $(n=32)$. Table 1 shows the clinicopathologic data and $M C A K$ mRNA expression ratio of cancerous to normal tissue $(\mathrm{T} / \mathrm{N})$ from the 65 gastric cancer patients. The incidences of lymph node metastasis $(P=0.04)$ and lymphatic invasion $(P=0.01)$ were significantly higher in the highexpression group than in the low-expression group. There were no significant differences seen between the other observed clinicopathological factors that were compared between the two expression groups. Moreover, the 5-year actuarial overall survival rates in patients with a high $M C A K$ expression ratio and patients

Table I Relationship between MCAK status and other variables

\begin{tabular}{|c|c|c|c|}
\hline & \multicolumn{2}{|c|}{ MCAK expression (T/N) } & \multirow[b]{2}{*}{$P$-values" } \\
\hline & High $^{a}(\%)$ & Low $^{a}(\%)$ & \\
\hline Number of tumours & 32 & 33 & - \\
\hline Average age $^{\mathrm{a}}$ (years) & $64.6 \pm 2.4$ & $65.1 \pm 2.3$ & 0.87 \\
\hline \multicolumn{4}{|l|}{ Sex } \\
\hline Female & $9(28.1)$ & $14(42.4)$ & \\
\hline Male & $23(71.9)$ & $19(57.6)$ & 0.23 \\
\hline \multicolumn{4}{|l|}{ Serosal invasion } \\
\hline+ & $12(37.5)$ & II (33.3) & \\
\hline- & $20(62.5)$ & $22(66.7)$ & 0.73 \\
\hline \multicolumn{4}{|l|}{ Lymphatic invasion } \\
\hline+ & $26(81.3)$ & $17(51.5)$ & \\
\hline- & $6(18.8)$ & $16(48.5)$ & 0.01 \\
\hline \multicolumn{4}{|l|}{ Lymph node metastasis } \\
\hline+ & $24(75.0)$ & $16(48.5)$ & \\
\hline- & $8(25.0)$ & $16(48.5)$ & 0.04 \\
\hline \multicolumn{4}{|l|}{ Vascular invasion } \\
\hline+ & $9(28.1)$ & $4(12.1)$ & \\
\hline- & $23(71.9)$ & $29(87.9)$ & 0.10 \\
\hline \multicolumn{4}{|l|}{ Liver metastasis } \\
\hline+ & $9(28.1)$ & I (3.0) & \\
\hline- & $23(71.9)$ & $32(97.0)$ & 0.28 \\
\hline \multicolumn{4}{|l|}{ Histology ${ }^{\mathrm{b}}$} \\
\hline Well & | (3.1) & $4(12.1)$ & \\
\hline Mod. & $12(37.5)$ & $6(18.2)$ & \\
\hline Poor & $9(28.1)$ & $13(39.4)$ & 0.10 \\
\hline
\end{tabular}

MCAK = mitotic centromere-associated kinesin; $\mathrm{T} / \mathrm{N}=$ ratio of cancerous to normal tissue. ${ }^{a}$ High and low: a group of patients with the higher and the lower T/N expression of MCAK than the median T/N level, respectively. 'Well, welldifferentiated adenocarcinoma; mod., moderately differentiated adenocarcinoma; poor, poorly differentiated adenocarcinoma. * Correlation was analysed by the $\chi^{2}$ method. Statistical significance between patients of MCAK high and low was observed in the incidence of lymphatic permeation (0.01) as well as lymph node metastasis (0.04). with a low $M C A K$ expression ratio were 45 and $79 \%$, respectively (Figure 2). The survival difference between these two groups was statistically significant $(P=0.008)$. Multivariate analysis indicated that the median expression ratio of $M C A K$ was found to be an independent and significant prognostic factor for survival (OR, 1.95; CI, 1.21-3.36) (Table 2).

\section{Experimental studies}

In vitro proliferation and cell cycle assays To estimate whether high $M C A K$ expression affects cell growth rates, the MCAK gene was transfected into the gastric cancer cell line AZ521 (Figure 3A), and a proliferation assay was performed. As shown in Figure 3B, there was a significant difference in the growth rate between the $M C A K$ - and the mock-transfected cells $(P<0.001)$. Between original cells and mock-transduced cells, there was no significant difference in the proliferation assays (data not shown). To investigate whether the $M C A K$-transfected cells showed high proliferative activity, the cell cycle was analysed. The percentage of cells in G1-, S-, and G2 + M phase of MCAK-transfected cells were $44.5 \pm 4.62,40.9 \pm 11.9$, and $6.43 \pm 5.83$, respectively. On the other hand, the percentage of cells in G1-, S-, and G2 + M phase of mock-transfected cells were $65.5 \pm 2.68,16.3 \pm 4.71$, and $17.1 \pm 8.87$, respectively. The percentage of cells in $\mathrm{S}$ phase of $M C A K-$ transfected cells was higher than the percentage of mocktransfected cells in $\mathrm{S}$ phase, following treatment with serum starvation for $24 \mathrm{~h}$ and serum refeeding for $18 \mathrm{~h}$ (Figure 3C). These results suggest the possibility that MCKA gene expression would be associated with cell proliferation because of increased cell cycling in gastric cancer cells.

In vitro migration and anoikis assays Whether MCAK expression would alter the migratory ability of AZ521 gastric cancer cells was

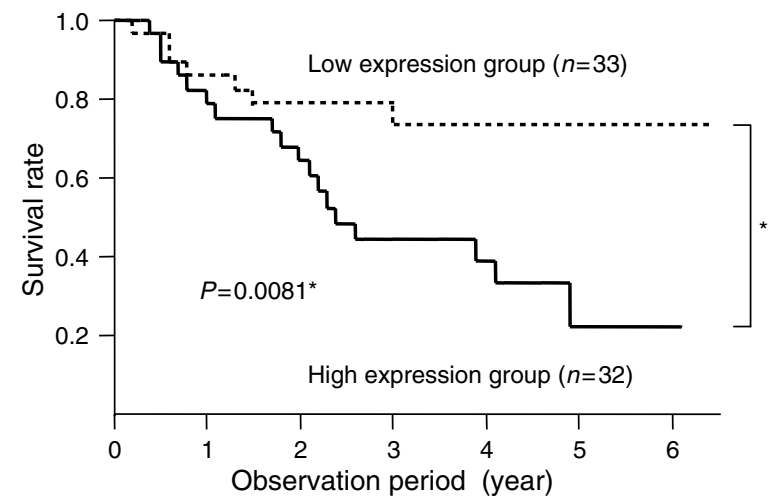

Figure 2 Overall survival rate of patients with gastric cancer grouped according to MCAK mRNA expression status of the tumour. Patients with high MCAK mRNA expression $(n=32)$ had a significantly poorer prognosis than those with low MCAK mRNA expression $(n=33)$.

Table 2 Multivariate analysis for overall survival

\begin{tabular}{lccc}
\hline Variables & Odds ratio & $\mathbf{9 5 \%} \mathbf{~ C l}$ & P-values \\
\hline Lymph node metastasis & 4.18 & $(1.87-17.86)$ & $<0.001^{\ddagger}$ \\
Vascular invasion & 0.98 & $(0.60-1.53)$ & 0.947 \\
Serosal invasion $^{\text {MCAK expression }}{ }^{\mathrm{a}}$ & 1.54 & $(1.02-2.33)$ & $0.039^{\ddagger}$ \\
\hline
\end{tabular}

$\mathrm{Cl}=$ confidence interval; $\mathrm{MCAK}=$ mitotic centromere-associated kinesin. ${ }^{\mathrm{a}}$ The hazard ratio of the higher MCAK expression compared to the lower expression for cancer death. ${ }^{\ddagger} P<0.05$ indicates an independent and significant prognostic factor for overall survival. 

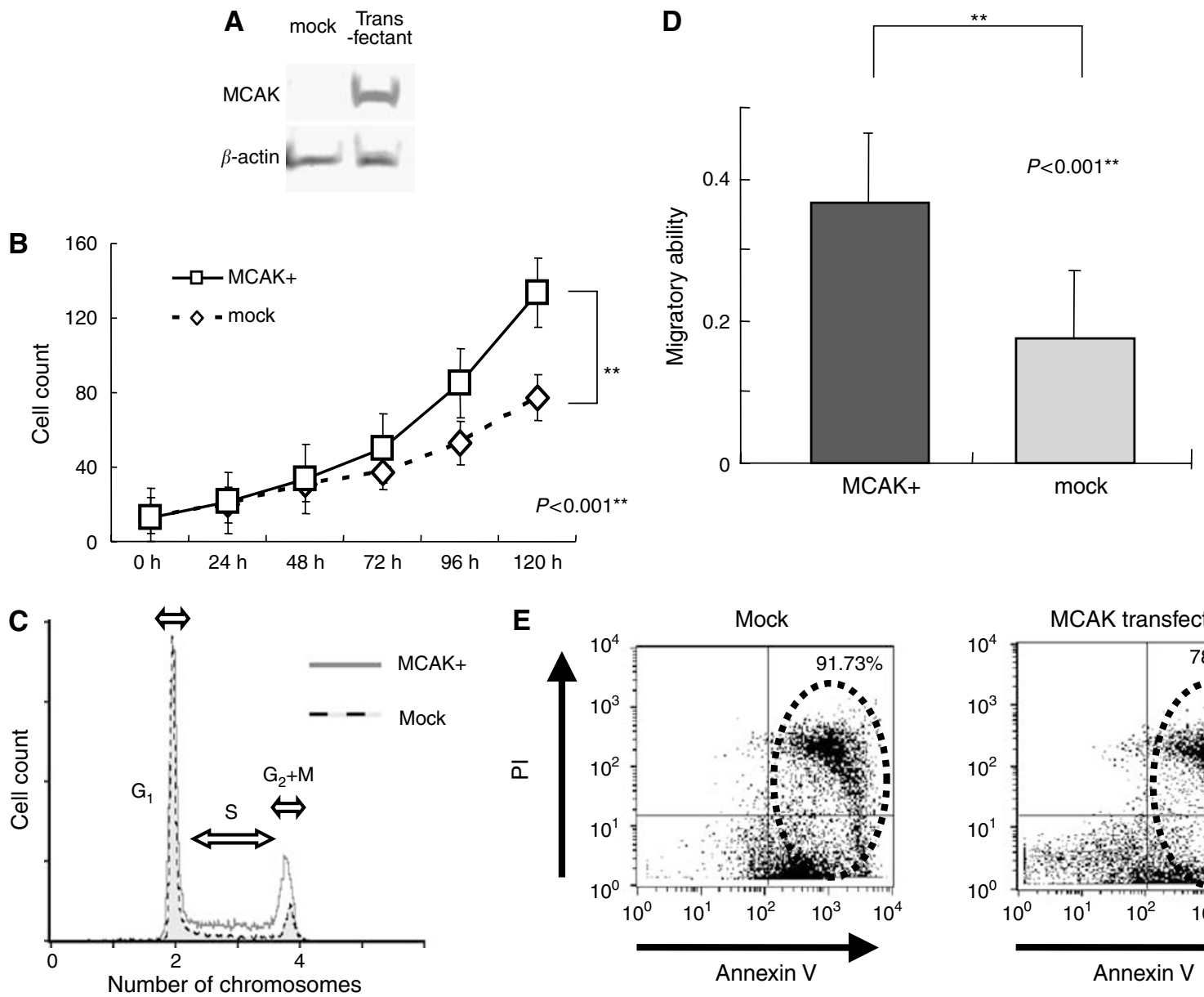

$$
P<0.001^{\star \star}
$$
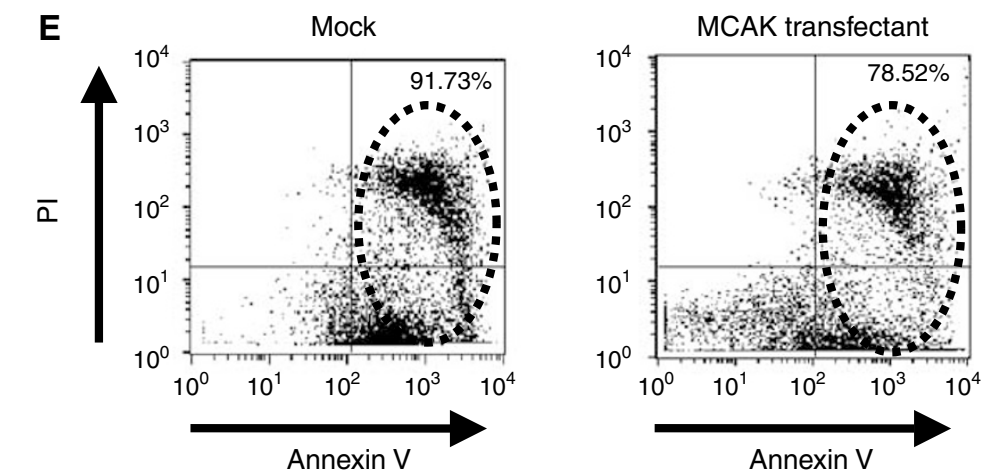

Figure 3 Experimental studies. (A) Western blotting revealed that MCAK protein was detected in transfectants but not in mock-transfected cells. $\beta$-Actin was used as a control. Right and left lanes show transfected and mock-transfected cells (cell line AZ52I), respectively. (B) Growth rate of MCAK transfectants and mock-transfected cells in I0\% FBS. Bar =s.d.; cell counts were greater in MCAK transfectants than in mock-transfected cells $(P<0.00 \mathrm{I})$.

(C) Cell cycle analysis of MCAK transfectants and mock-transfected cells after $24 \mathrm{~h}$ of serum starvation followed by $18 \mathrm{~h}$ serum feeding with $10 \% \mathrm{FBS}$. The GI-phase cell counts were unified. The S-phase fraction was greater in transfectants (44.3\%) than mock-transfected cells (25.3\%). (D) Migration assay. The migratory ability of transfectants was significantly stronger than that of mock-transfected cells $(P<0.00 \mathrm{I})$. (E) Anoikis analysis. After anoikis induction for I $8 \mathrm{~h}$, the apoptosis rate was measured by annexin $\mathrm{V}$ and PI staining. Proportion of apoptotic MCAK-transfected cells (78.52\%) was less than that of apoptotic mock-transfected cells (91.73\%)

assessed in a migration assay in the condition of 24,36 , and $48 \mathrm{~h}$. In all conditions, transfectants demonstrated greater motility than mock transfectants $(P<0.001)$ (Figure 3D). This result corresponds to the results seen in analysed gastric cancer specimens that showed significant correlation between $M C A K$ expression and invasiveness.

Anoikis is associated with cellular migration and metastatic potential. After anoikis-induced cell culture, more mock-transfected cells $(91.73 \%)$ were apoptotic than $M C A K$-overexpressing cells $(78.52 \%)$. MCAK-overexpressing cells appeared to be more resistant to anoikis induction than mock-transfected cells (Figure 3E). This anoikis assay was performed three times, and all assays revealed same results.

\section{DISCUSSION}

Microtubules, vital components of the cytoskeleton, play important roles in mitosis, cell migration, cell signaling, and trafficking (Honore et al, 2005). Identification of proteins regulating the MT network of cancer cells could lead to a better understanding of regulation of tumour progression and will be helpful in improving cancer therapy. Therefore, we have investigated MCAK, which controls MT dynamics.

To clarify the aggressive behaviour of tumours with MCAK overexpression, we used in vitro assays to analyse the function of MCAK in cancer cells. Gastric cancer cells transfected with MCAK demonstrated higher migratory rates and greater resistance to anoikis than mock-transfected cells. It was reported that knockdown of KIF2A, which has a similar function to MCAK as an MT depolymerase, results in loss of motility in nerve cells (Homma et al, 2003). Thus, Kin1 kinesins, such as KIF2A and MCAK, may regulate cell motility. The results of cell motility experiments may partly explain our finding that gastric cancer patients with tumours that express high levels of MCAK had higher rates of lymphatic invasion and metastasis, and a poorer prognosis.

The regulators of MT dynamics are important for control of chromosome movement and mitosis (Gigant et al, 2000; Howell et al, 2001; Ichihara et al, 2001). As for these regulators in cancer cells, the catastrophe factors of MTs such as oncoprotein (Op)18/ stathmin were reported to be overexpressed in a number of human malignancies, and to be associated with cancer progression and prognosis (Roos et al, 1993; Bieche et al, 1998a, b; Brattsand, 2000; Chen et al, 2003; Moore and Wordeman, 2004; Kouzu et al, 2006). 
Op18/stathmin is involved in the cell cycle and contributes to tumorigenesis and proliferation. Suppression of Op18/stathmin expression interferes with cell cycle progression (Melhem et al, 1991; Jeha et al, 1996; Mistry and Atweh, 2002). The present study has revealed that cancer cells overexpressing MCAK, also a regulator of MT dynamics, showed high proliferative ability compared with mock-transfected cells. In addition, cell cycles of MCAK-expressing cells were faster than cell cycles of mock-transfected cells. These results may also contribute to the explanation of the aggressive behaviour of MCAK-overexpressing tumours.

MCAK has potential as a therapeutic target. The sulfoquinovosylacylglycerols (SQAGs) found in ferns and algae were reported as novel anticancer agents that inhibit DNA polymerase (Ohta et al, 2001). Recently, Aoki et al (2005) reported that the target of SQAGs was not only DNA polymerase, but also MCAK. Some SQAGs studies have demonstrated good antitumour effects (Sahara $e t$ al, 1997; Matsumoto et al, 2002). These results, combined with our findings, suggest that this novel anticancer agent may be effective in gastric cancer patients with tumours that overexpress MCAK.

In normal human organs, MCAK gene expression is distributed only in the testis (Scanlan et al, 2002). Our pilot study illustrated the same result (data not shown). From SAGE analysis (www.cgap.gov), MCAK was found to be highly expressed in testis and ovaries, which contain meiotic cells and a high number of proliferating cells. Mitotic centromere-associated kinesin is expressed in other tissue types at levels considered negligible. This suggests that MCAK could be a cancer testis antigen (CTA) and could become an immunotherapy target antigen. Immunotherapy, which uses tumour-specific peptides, RNA, or tumour lysate, is now considered one of the therapeutic strategies against advanced cancer (Gilboa et al, 1998; Sadanaga et al, 2001; Shimizu et al, 2001). We previously reported on the expression of MAGE-1 and MAGE-3 in several cancers (Inoue et al, 1995), and we identified several MAGE peptides that are recognised by cytotoxic T lymphocytes (Tanaka et al, 1997; Fujie et al, 1999). On the basis of these findings, cancer-specific immunotherapy using the HLA class I restricted MAGE peptide has been used in our institution for patients with advanced cancers (Sadanaga et al, 2001). However, MAGE expression is restricted, and almost less than half of the tumours studied express MAGE. Thus, a novel CTA useful for immunotherapy is strongly recommended. We think that MCAK may be a candidate gene for cancer-specific immunotherapy.

It has also been reported that MCAK protein was detected from the blood of colon cancer patients by the SELEX method (Scanlan et al, 2002), suggesting that MCAK might be useful in diagnosis. We are now investigating whether the level of MCAK in the blood correlates with tumour progression or prognosis.

In summary, we confirmed that MCAK is a cancer-specific gene and that gastric tumours with MCAK expression were associated with lymphatic invasion, lymph node metastasis, and poor prognosis. Mitotic centromere-associated kinesin may become a molecular target of an anticancer drug or cancer-specific immunotherapy.

\section{ACKNOWLEDGEMENTS}

We thank Dr Linda Wordeman (Moore and Wordeman, 2004), University of Washington School of Medicine (Seattle, WA, USA) for kindly providing the $M C A K$ gene expressing vector (EGFPHsMCAK). We thank Drs K Ieta, S Hirasaki, Y Kosaka, T Yokoe, Z Xiang, and A Sasaki for critical reading of the paper. We also thank Ms T Shimooka, Ms K Ogata, Ms M Oda, Ms N Kasagi, and Ms Y Nakagawa for their excellent technical assistance. This work was supported by the following grant sponsors: CREST, Japan Science and Technology Agency (JST); Japan Society for the Promotion of Science (JSPS) Grant-in-Aid for Scientific Research, Grant nos. 17109013, 17591411, 17591413, 18390367, 18590333, 18659384, and 18790964; The Ministry of Education, Culture, Sports, Science and Technology (MEXT) Grant-in-Aid for Scientific Research on Priority Areas, Grant no. 18015039; Third Term Comprehensive Ten-year Strategy for Cancer Control, Grant no. 16271201.

\section{REFERENCES}

Adrain C, Slee EA, Harte MT, Martin SJ (1999) Regulation of apoptotic protease activating factor- 1 oligomerization and apoptosis by the WD-40 repeat region. J Biol Chem 274: 20855-20860

Albini A, Iwamoto Y, Kleinman HK, Martin GR, Aaronson SA, Kozlowski JM, McEwan RN (1987) A rapid in vitro assay for quantitating the invasive potential of tumor cells. Cancer Res 47: 3239-3245

Aoki S, Ohta K, Yamazaki T, Sugawara F, Sakaguchi K (2005) Mammalian mitotic centromere-associated kinesin (MCAK): a new molecular target of sulfoquinovosylacylglycerols novel antitumor and immunosuppressive agents. FEBS J 272: 2132-2140

Bieche I, Lachkar S, Becette V, Cifuentes-Diaz C, Sobel A, Lidereau R, Curmi PA (1998a) Overexpression of the stathmin gene in a subset of human breast cancer. Br J Cancer 78: $701-709$

Bieche I, Olivi M, Champeme MH, Vidaud D, Lidereau R, Vidaud M (1998b) Novel approach to quantitative polymerase chain reaction using real-time detection: application to the detection of gene amplification in breast cancer. Int J Cancer 78: 661-666

Bieche I, Onody P, Laurendeau I, Olivi M, Vidaud D, Lidereau R, Vidaud M (1999) Real time reverse transcription-PCR assay for future management of ERBB2-based clinical applications. Clin Chem 45: 1148-1156

Brady ST (1985) A novel brain ATPase with properties expected for the fast axonal transport motor. Nature 317: 73-75

Brattsand G (2000) Correlation of oncoprotein 18/stathmin expression in human breast cancer with established prognostic factors. Br J Cancer 83: $311-318$

Chen G, Wang H, Gharib TG, Huang CC, Thomas DG, Shedden KA, Kuick R, Taylor JM, Kardia SL, Misek DE, Giordano TJ, Iannettoni MD, Orringer MB, Hanash SM, Beer DG (2003) Overexpression of onco-

protein 18 correlates with poor differentiation in lung adenocarcinomas. Mol Cell Proteomics 2: 107-116

Endow SA (2003) Kinesin motors as molecular machines. Bioessays 25: $1212-1219$

Fujie T, Tahara K, Tanaka F, Mori M, Takesako K, Akiyoshi T (1999) A MAGE-1-encoded HLA-A24-binding synthetic peptide induces specific anti-tumor cytotoxic $\mathrm{T}$ lymphocytes. Int $J$ Cancer 80: $169-172$

Gigant B, Curmi PA, Martin-Barbey C, Charbaut E, Lachkar S, Lebeau L, Siavoshian S, Sobel A, Knossow M (2000) The $4 \AA$ X-ray structure of a tubulin:stathmin-like domain. Cell 102: 705-862

Gilboa E, Nair SK, Lyerly HK (1998) Immunotherapy of cancer with dendritic-cell-based vaccines. Cancer Immunol Immunother 46: 82 - 87

Helenius J, Brouhard G, Kalaidzidis Y, Diez S, Howard J (2006) The depolymerizing kinesin MCAK uses lattice diffusion to rapidly target microtubule ends. Nature 441: 115-119

Hirokawa N, Pfister KK, Yorifuji H, Wagner MC, Brady ST, Bloom GS (1989) Submolecular domains of bovine brain kinesin identified by electron microscopy and monoclonal antibody decoration. Cell 56: $867-878$

Holmfeldt P, Stenmark S, Gullberg M (2004) Differential functional interplay of TOGP/XMAP215 and the KinI kinesin MCAK during interphase and mitosis. EMBO J 23: 627-637

Homma N, Takei Y, Tanaka Y, Nakata T, Terada S, Kikkawa M, Noda Y, Hirokawa N (2003) Kinesin superfamily protein 2A (KIF2A) functions in suppression of collateral branch extension. Cell 114: 229-239

Honore S, Pasquier E, Braguer D (2005) Understanding microtubule dynamics for improved cancer therapy. Cell Mol Life Sci 62: 3039-3056 
Howell BJ, McEwen BF, Canman JC, Hoffman DB, Farrar EM, Rieder CL, Salmon ED (2001) Cytoplasmic dynein/dynactin drives kinetochore protein transport to the spindle poles and has a role in mitotic spindle checkpoint inactivation. J Cell Biol 155: 1159-1172

Ichihara K, Kitazawa H, Iguchi Y, Hotani H, Itoh TJ (2001) Visualization of the stop of microtubule depolymerization that occurs at the high-density region of microtubule-associated protein 2 (MAP2). J Mol Biol 312: $107-118$

Inoue $\mathrm{H}$, Mori $\mathrm{M}$, Honda $\mathrm{M}$, Li J, Shibuta $\mathrm{K}$, Mimori $\mathrm{K}$, Ueo $\mathrm{H}$, Akiyoshi $\mathrm{T}$ (1995) The expression of tumor-rejection antigen 'MAGE' genes in human gastric carcinoma. Gastroenterology 109: $1522-1525$

Jeha S, Luo XN, Beran M, Kantarjian H, Atweh GF (1996) Antisense RNA inhibition of phosphoprotein p18 expression abrogates the transformed phenotype of leukemic cells. Cancer Res 56: 1445-1450

Jemal A, Tiwari RC, Murray T, Ghafoor A, Samuels A, Ward E, Feuer EJ, Thun MJ, American Cancer Society (2004) Cancer statistics. CA Cancer J Clin 54: 8-29

Kaplan EL, Meier P (1958) Nonparametric estimation from incomplete observations. J Am Stat Assoc 53: 457-481

Kline-Smith SL, Walczak CE (2002) The microtubule-destabilizing kinesin XKCM1 regulates microtubule dynamic instability in cells. Mol Biol Cell 13: $2718-2731$

Kouzu Y, Uzawa K, Koike H, Saito K, Nakashima D, Higo M, Endo Y, Kasamatsu A, Shiiba M, Bukawa H, Yokoe H, Tanzawa H (2006) Overexpression of stathmin in oral squamous-cell carcinoma: correlation with tumour progression and poor prognosis. Br J Cancer 94: 717-723

Maney T, Hunter AW, Wagenbach M, Wordeman L (1998) Mitotic centromere-associated kinesin is important for anaphase chromosome segregation. J Cell Biol 142: 787-801

Mantel N (1966) Evaluation of survival data and two new rank order statistics arising in its consideration. Cancer Chemother Rep 50: $163-170$

Matsumoto Y, Sahara H, Fujita T, Shimozawa K, Takenouchi M, Torigoe T, Hanashima S, Yamazaki T, Takahashi S, Sugawara F, Mizushina Y, Ohta K, Takahashi N, Gasa S, Jimbow K, Sakaguchi K, Sato N (2002) An immunosuppressive effect by synthetic sulfonolipids deduced from sulfonoquinovosyl diacylglycerols of sea urchin. Transplantation 74: $261-267$

Melhem RF, Strahler JR, Hailat N, Zhu XX, Hanash SM (1991) Involvement of OP18 in cell proliferation. Biochem Biophys Res Commun 179: $1649-1655$

Mistry SJ, Atweh GF (2002) Role of stathmin in the regulation of the mitotic spindle: potential applications in cancer therapy. Mt Sinai J Med 69: 299-304

Moore A, Wordeman L (2004) The mechanism, function and regulation of depolymerizing kinesins during mitosis. Trends Cell Biol 14: 537-546

Mori M, Barnard GF, Staniunas RJ, Jessup JM, Steele GD, Chen LB (1993) Prothymosin- $\alpha$ mRNA expression correlates with that of c-myc in human colon cancer. Oncogene 8: 2821 -2826
Ogawa K, Utsunomiya $\mathrm{T}$, Mimori $\mathrm{K}$, Tanaka $\mathrm{Y}$, Tanaka $\mathrm{F}$, Inoue $\mathrm{H}$, Murayama S, Mori M (2004) Clinical significance of elongation factor- $1 \delta$ mRNA expression in oesophageal carcinoma. Br J Cancer 91: 282-286

Ohta K, Mizushina Y, Yamazaki T, Hanashima S, Sugawara F, Sakaguchi K (2001) Specific interaction between an oligosaccharide on the tumor cell surface and the novel antitumor agents, sulfoquinovosylacylglycerols. Biochem Biophys Res Commun 288: 893-900

Perou CM, Jeffrey SS, van de Rijn M, Rees CA, Eisen MB, Ross DT, Pergamenschikov A, Williams CF, Zhu SX, Lee JC, Lashkari D, Shalon D, Brown PO, Botstein D (1999) Distinctive gene expression patterns in human mammary epithelial cells and breast cancers. Proc Natl Acad Sci USA 96: 9212 -9217

Roos G, Brattsand G, Landberg G, Marklund U, Gullberg M (1993) Expression of oncoprotein 18 in human leukemias and lymphomas. Leukemia 7: 1538-1546

Sadanaga N, Nagashima H, Mashino K, Tahara K, Yamaguchi H, Ohta M, Fujie T, Tanaka F, Inoue H, Takesako K, Akiyoshi T, Mori M (2001) Dendritic cell vaccination with MAGE peptide is a novel therapeutic approach for gastrointestinal carcinomas. Clin Cancer Res 7: 2277-2284

Sahara H, Ishikawa M, Takahashi N, Ohtani S, Sato N, Gasa S, Akino T, Kikuchi K (1997) In vivo anti-tumour effect of $3^{\prime}$-sulphonoquinovosyl $1^{\prime}$-monoacylglyceride isolated from sea urchin (Strongylocentrotus intermedius) intestine. Br J Cancer 75: 324-332

Sakamoto J, Morita S, Kodera Y, Rahman M, Nakao A (2004) Adjuvant chemotherapy for gastric cancer in Japan: global and Japanese perspectives. Cancer Chemother Pharmacol 54(Suppl 1): S25-S31

Scanlan MJ, Welt S, Gordon CM, Chen YT, Gure AO, Stockert E, Jungbluth AA, Ritter G, Jäger D, Jäger E, Knuth A, Old LJ (2002) Cancer-related serological recognition of human colon cancer: identification of potential diagnostic and immunotherapeutic targets. Cancer Res 62: $4041-4047$

Shimizu K, Thomas EK, Giedlin M, Mulé JJ (2001) Enhancement of tumor lysate- and peptide-pulsed dendritic cell-based vaccines by the addition of foreign helper protein. Cancer Res 61: 2618-2624

Tanaka F, Fujie T, Tahara K, Mori M, Takesako K, Sette A, Celis E, Akiyoshi $\mathrm{T}$ (1997) Induction of antitumor cytotoxic T lymphocytes with a MAGE3 -encoded synthetic peptide presented by human leukocytes antigenA24. Cancer Res 57: 4465-4468

Terry MB, Gaudet MM, Gammon MD (2002) The epidemiology of gastric cancer. Semin Radiat Oncol 12: $111-127$

Vale RD, Reese TS, Sheetz MP (1985) Identification of a novel forcegenerating protein, kinesin, involved in microtubule-based motility. Cell 42: $39-50$

Wittmann T, Hyman A, Desai A (2001) The spindle: a dynamic assembly of microtubules and motors. Nat Cell Biol 3: 28-34

Wordeman L, Mitchison TJ (1995) Identification and partial characterization of mitotic centromere-associated kinesin, a kinesin-related protein that associates with centromeres during mitosis. J Cell Biol 128: 95-104 